\title{
Web 2.0 \\ (Antonio Fumero, Genís Roca y Fernando Sáez Vacas)
}

\author{
Por Dídac Margaix-Arnal
}

Margaix-Arnal, Dídac. “Web 2.0 (Antonio Fumero, Genís Roca y Fernando Sáez Vacas)”. En: El profesional de la información, 2007, julio-agosto, v. 16, n. 4, pp. 385-386.

DOI: 10.3145/epi.2007.jul.15

TODO LO QUE HACE REFERENCIA A LA WEB 2.0 está generando gran interés tanto dentro como fuera de nuestra profesión. Para algunos este interés es desmedido, para otros está justificado por encontrarnos en un punto de inflexión de las relaciones de las organizaciones con sus clientes y usuarios.

Los autores que han estudiado la aplicación de los blogs a las empresas destacan que éstas los utilizan, y por extensión todas las herramientas 2.0, con una triple intención: escuchar, conversar e influir. Esa es la nueva filosofía de la relación con el usuario, una filosofía que las unidades de información también han de aplicar. Se ha de pasar de la comunicación hacia los usuarios a una conversación con ellos.

El libro editado recientemente por la Fundación Orange con el título tan simple y directo de "Web 2.0" nos puede ayudar a entender este nuevo proceso de conversación, por qué es necesario, con qué herramientas contamos y por qué la sociedad espera esa actitud de las organizaciones.

La obra se estructura en tres partes muy diferenciadas y redactadas por cada uno de los tres autores: Antonio Fumero, Genís Roca y Fernando Sáez Vacas. Fumero es ingeniero en Telecomunicaciones y tras pasar unos años en la Unidad de Investigación y Desarrollo Tecnológico del BBVA se incorporó al Departamento de Ingeniería de Sistemas Telemáticos de la Univer-

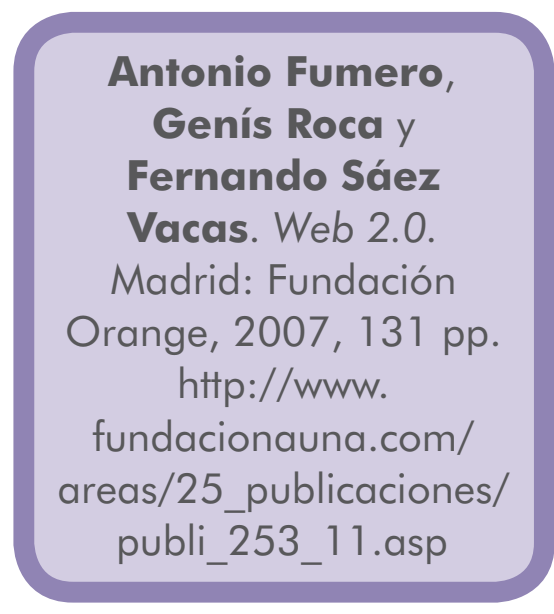

sidad Politécnica de Madrid; Roca es licenciado en historia y master en dirección y administración de empresas, ha sido responsable del modelo de presencia en internet de la Universitat Oberta de Catalunya $y$ en la actualidad es director general de Infonomía; y Sáez Vacas es doctor ingeniero en telecomunicaciones y tiene una dilatada carrera como autor de numerosos artículos y libros científicos.

La primera parte de la monografía, elaborada por Fumero, es un amplio y erudito análisis del entorno sociotécnico que ha dado origen a la web 2.0. Su estudio se enmarca en un objeto de análisis más amplio que denomina Web de nueva generación, donde la situación actual sólo es un paso hacia esa red de mayores prestaciones y mayor alcance.

Realiza su estudio desde la sociología, y analiza los cambios sociológicos que introdujeron las tecnologías 1.0 y han posibilitado la aparición de los servicios 2.0, pero no detiene ahí su investigación, y continúa con una prospección de cómo la web semántica nos puede llevar a la 3.0 y a la de nueva generación. Finaliza este capítulo con un análisis de las implicaciones culturales y sociales de las principales tecnologías "dospuntoceristas": los blogs, el software social y las wikis.

En la segunda parte del libro, Roca repasa el contexto económico y social de la web actual, en tres apartados donde se analizan por separado los intereses de las personas, de las organizaciones y del capital en los servicios 2.0. El autor repasa los motivos por los que determinadas personas participan en los proyectos de inteligencia social, aportando su tiempo y su conocimiento de forma desinteresada. Seguidamente sitúa los motivos por

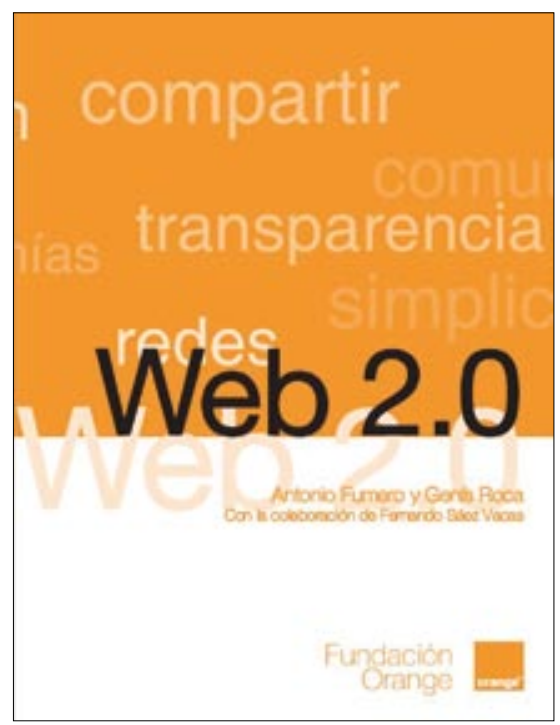


los que las empresas están interesadas o deben preocuparse por la web 2.0 en general y por la blogosfera en particular. Describe los modelos de negocio existentes en los servicios 2.0, las fórmulas que se están desarrollando para obtener beneficios. Cierra su capítulo un análisis de los movimientos económicos buscando las diferencias con la situación que llevó a la creación y el posterior estallido de la burbuja tecnológica en 2001.

El último apartado del libro firmado por Sáez Vacas ofrece una contextualización sociotécnica de la web 2.0. Esta parte está sin duda muy conectada con la primera del libro. Aquí el autor profundiza en algunos conceptos como "Red universal digital", "Noomorfosis digital" o "blogólogo", todos ellos acuñados por él mismo. Destaca su preocupación por el escaso interés que se presta al estudio de las implicaciones culturales y sociales de las novedades tecnológicas y cómo éstas son asumidas sin valorar sus consecuencias en nuestro entorno y en nuestra sociedad.

Junto al libro, la Fundación Orange ha publicado un mapa de la web 2.0, una interesante propuesta donde, con una excelente organización visual, se recogen las definiciones de los principales elementos de la nueva generación de servicios web, separando los más filosóficos (o actitudinales) de los más técnicos. Junto a ellos y agrupados por tipo de servicio, las experiencias de mayor éxito en la web actual.
En conclusión este libro permite al lector alejarse de la vorágine de novedades que surgen todos los días sobre la web 2.0 y reflexionar sobre cómo se ha llegado a esta situación, qué cambios sociales se han producido y cuáles puede que estén por llegar. Permite contextualizar las tecnologías en la sociedad que las produce y las consume, haciendo que el lector se plantee el papel social que juegan las novedades tecnológicas que nos rodean.

Dídac Margaix-Arnal, Biblioteca de la Universitat Politècnica de València.

DosPuntoCero.

http://dospuntocero.dmaweb.info/ diemarar@bib.upv.es

\section{IweTel}

Es un foro electrónico de debate, puesto en marcha por EPI - El profesional de la información, sobre información, documentación, biblioteconomía y sus tecnologías, con unos 4.500 suscriptores.

Para inscribirse en IweTel hay que enviar a la dirección:

listserv@rediris.es

un mensaje en cuyo cuerpo figure:

subscribe iwetel Nombre Apellido

Una vez inscrito, se puede participar en IweTel remitiendo los mensajes a:

iwetel@listserv.rediris.es

Más información en:

http://www.rediris.es/list/info/iwetel.html 